\title{
Analysis of Velocity Sedimentation Techniques in Cell Separation Influence of Apparative and Sample Properties on Separative Power, Resolution and Sensitivity
}

\author{
Klaus Zeiller, Ernil Hansen, Dieter Leihener, Gertrud Pascher and Hans Wirth \\ Max-Planck-Institut für Biochemie, Martinsried bei München
}

(Received 21 May 1976)

Summary: In the present investigation the velocity sedimentation technique was analysed with respect to separation resolution, power and sensitivity. It was found that apparative modifications do not influence the resolution, which is a function of the contribution of apparative errors to the dispersion. A surprisingly small parameter of 0.15 was determined and it seems unlikely that this value can be improved. On the other hand an apparative modification is presented which improves the separation power and makes sample loading independent of the gradient filling. If cells (from rat bone marrow) were separated, a several times higher dispersion for a given cell volume was observed than was due to the apparative error. It was concluded that density variations were the major source of this dispersion. Since cell volume and density apparently show independent variations within a biological cell population the cell density cannot be disregarded if velocity sedimentation profiles are discussed in physical terms as is often done.

\section{Analyse von ,Velocity Sedimentation“ Techniken im Hinblick auf die Trennung von Zellen Einfluß der Eigenschaften von Apparatur und Probe auf Trennleistung, Auflösungsvermögen und Empfindlichkeit}

Zusammenfassung: In der vorliegenden Arbeit wurde die Technik der „Velocity Sedimentation“ hinsichtlich Auflösungsvermögen, Trennleistung und Empfindlichkeit untersucht. Das Auflösungsvermögen konnte durch apparative Modifikationen nicht verbessert werden. Für die Dispersion, die auf apparative Fehler zurückzuführen ist, wurde ein überraschend niedriger Wert von 0.15 gefunden. Es ist wenig wahrscheinlich, daß dieses Ergebnis noch verbessert werden kann. Durch die beschriebenen apparativen Modifikationen kann jedoch einerseits die Trennleistung wesentlich erhöht werden, andererseits geschieht das Aufbrin- gen der Partikelsuspension unabhängig vom Einfüllen des Gradienten. Für Zellen (Ratten-Knochenmark) wurde im Vergleich zu Latex-Partikeln von gleichen Volumen eine wesentlich höhere Dispersion ermittelt. Es ist anzunehmen, daß Hauptursache für diese durch apparative Fehler nicht erklärbare, relativ hohe Dispersion Dichtestreuungen innerhalb der Zellpopulationen sind. Da Volumen und Dichte innerhalb einer biologischen Zellpopulation unabhängig voneinander variieren können, darf die Zell-Dichte bei der Diskussion von Sedimentationsprofilen nicht außer Acht gelassen werden, wie es oft geschieht.

Key words: Cell separation, velocity sedimentation, bone marrow cells, sedimentation of cells. 
Cells can be separated on the basis of size differences into populations different either in functions or in cell cycle phase ${ }^{[1]}$. The separation techniques available are electronic cell sorting and velocity sedimentation ${ }^{[2,3]}$. Velocity sedimentation is the most frequently used method due to its technical simplicity and reasonably good resolution. The usual technique is that described by Peterson and Evans ${ }^{[4]}$ and Miller and Phillips ${ }^{[5]}$, using a cylindrical separation chamber with a conically formed base with a central inlet. The cell sample is placed into the cone of the chamber and is lifted to its starting position by an incoming gradient solution from serum. After cell sedimentation the gradient is drained via the bottom or top of the chamber. The discontinuous separation system is relatively limited in separation power and the dispersion is higher than theoretically expected ${ }^{[4-7]}$. Basically the dispersion can be classified into particle dependent factors and errors due to the method. Since the latter factor may be influenced by appropriate apparative modifications it was attempted 1. to define dispersion factors better and 2 . to analyse various modifications of chamber filling and draining and sample application techniques with respect to resolution and separation power.

\section{Methods}

\section{Sedimentation chambers}

In the present study two sedimentation chambers were used. Both chambers consisted of a Jena-glass cylinder of $186 \mathrm{~mm}$ inner diameter and $150 \mathrm{~mm}$ height. in the one chamber this cylinder was fixed to a conically shaped base with a central inlet (inner diameter $1.6 \mathrm{~mm}$ ) as described by Miller and Phillips ${ }^{[5]}$. In the other chamber the glass cylinder was fixed to a teflon-coated plane V2A steel plate as shown in Fig. 1. The base plate contained 92 conically shaped bores (outer diameter $15 \mathrm{~mm}$ ) which were regularly distributed over the chamber area. Steel needles $(0.7 \mathrm{~mm}$ inner diameter $)$ were fixed in these bores. From these needles silicone tubes $(0.5 \mathrm{~mm}$ inner diameter) led to a 92 channel peristaltic pump with only poor pulsation (Garching Instruments, Garching, Munich). All tubes having identical length were then combined and were connected either with the fraction collector or the gradient mixer. Since the pump allowed reversible flow directions the chamber could be filled and drained at any flow rate desired $(3 \mathrm{ml} / \mathrm{min}-50 \mathrm{ml} / \mathrm{min})$. The error in the flow rate per tube was less than $1 \%$.

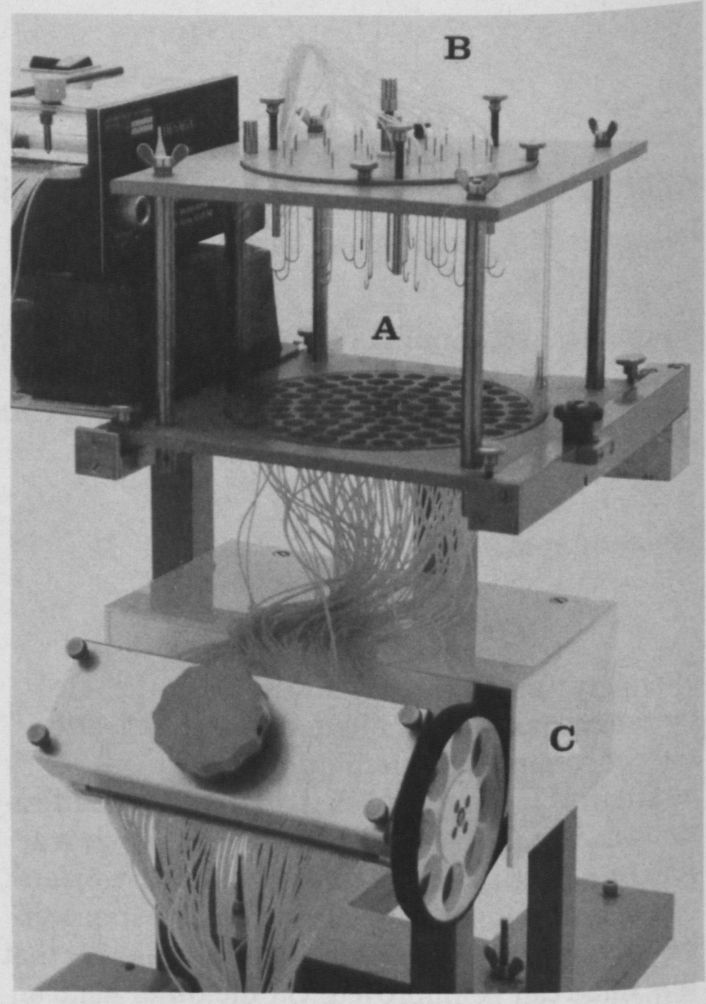

Fig. 1. Velocity sedimentation equipment.

A) Separation chamber; B) sample applicator;

C) Peristaltic pump.

\section{Gradient}

A calf serum gradient ( $\mathrm{pH}$ 7.4) was prepared by means of an electronic gradient mixer (Ultrograd, LKB)

(Fig. 2). The stock solutions were a 20\% serum dilution in TC solution Puck-G (Difco) and a pure TC solution Puck-G. The linear gradient showed a buffered step on top as suggested by Miller and Phillips $[5]$ to reduce cell streaming. Mixing of the gradient was performed in a cylindrical chamber with $24 \mathrm{~mm} \times 48 \mathrm{~mm}$ inner diameter. The sedimentation chambers were filled to a height of $94 \mathrm{~mm}$. The serum concentration being $4 \%$ at the surface of the gradient increased steeply to $7 \%$ at a height of $84 \mathrm{~mm}$ and then linearly to $14 \%$ at the base of the cylinder. All operations were performed at $4{ }^{\circ} \mathrm{C}$. The density and viscosity of the gradient was determined at $4{ }^{\circ} \mathrm{C}$. Sedimentation velocities were calculated as described ${ }^{[1]}$.

\section{Sample application}

The separation sample was loaded by means of two different techniques. If a chamber was used with a 


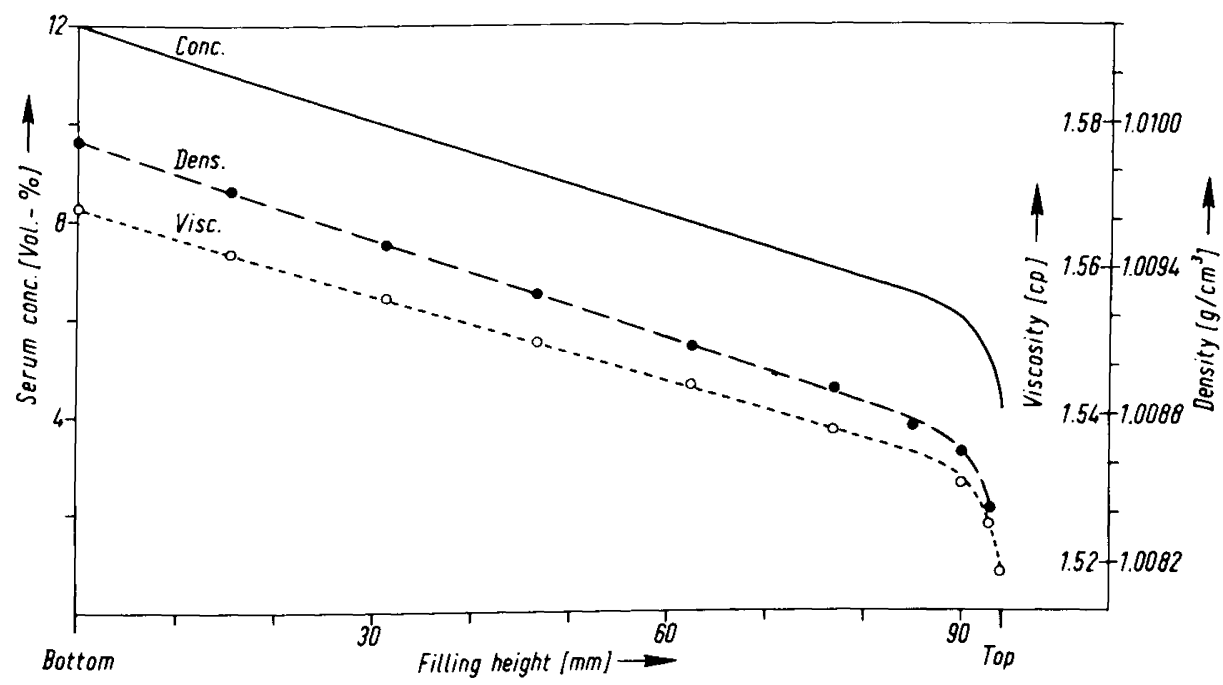

Fig. 2. Concentration, viscosity and density of the serum gradient in the sedimentation chamber.

conically shaped base with a central inlet the sample was lifted to its starting position by the incoming gradient. If a chamber was used with a plane base the sample was applied to the top of the gradient. For this purpose a metal plate with 25 regularly distributed and vertically mounted steel needles was placed on top of the separation chamber. The ends reaching into the chamber were bent so that their outlets pointed vertically upwards, being at the same level as the gradient surface. Outside the chamber the needles were attached to silicone tubes which led over a peristaltic pump to the sample container.

\section{Electronical cell sizing}

The particle volumes were determined by means of an electronic volume analyser according to Thom et al. $[8]$. The apparatus consisted of a partical detector MS DK 1-1105/1, a preamplifier MS KV 1-1105/1, a power supply MS HS 4-1105/1 and a multichannel analyser MS VAS 1105 (AEG-Telefunken, Ulm, Germany). The detector capillary had a diameter of $70 \pm 10 \mu \mathrm{m}$. The instrument was calibrated with $5 \mu \mathrm{m}$ and $7.9 \mu \mathrm{m}$ polystyrene particles (Particle Technology, Inc. Los Alamos). The size histograms were recorded by a X-Y recorder and analysed by means of a Hewlett Packard 9820 A Calculator.

\section{Particles}

The experiments were performed with Dow Latex 41961 particles of $5.7 \mu \mathrm{m}$ diameter (s.d., $1.5 \mu \mathrm{m}$ ) (Serva, Heidelberg) and Polystyrene Microspheres of $5 \mu \mathrm{m}$ and $7.9 \mu \mathrm{m}$ diameter (Particle Technology, Inc. Los Alamos).

\section{Bone marrow cells}

Bone marrow from adult Wistar rats was collected in TC solution Puck-G and dispersed by repeated aspiration into pipettes. The sample was filtered through thin layers of cotton wool, washed twice and adjusted to $5 \times 10^{6}$ cells $/ \mathrm{ml}$ in TC solution Puck-G.

\section{Results}

\section{Gradient disturbance}

The separation resolution can be impaired by mechanical disturbance of the gradient during filling and draining of the separation chamber and during loading of the starting band. (Thermodiffusion and convection may be disregarded at $4{ }^{\circ} \mathrm{C}$.)

1. The jet of the inflowing medium may disturb the shallow density gradient (which is necessary to stabilize the sedimenting bands). An increased dispersion of the sedimenting bands may be the consequence.

2. The same process may cause disturbance of the starting band if this is lifted to its starting position by the incoming gradient.

3. Disturbance of the buffer flow during drainage may cause broadening of the bands.

The major source of the gradient disturbance is the gradient flow rate during filling and draining 
which must not exceed a critical threshold at which nonlaminar flow occurs. A further apparative source may be the geometry and arrangement of the chamber inlets and outlets. In the following these variables were analysed using two different chambers, one showing a single inlet in a conically shaped base (vertical flow was prevented by a baffle ${ }^{\mid 4,5]}$ and the other showing 92 inlets placed regularly over a plane base (Fig. 1).

A shallow serum gradient was filled in to the chambers (Fig. 2). During the filling a $50 \mathrm{ml}$ portion of the gradient was stained with Trypan blue before entering the chamber. (Tailing was carefully avoided.) After complete filling the chamber was drained at a rate of $11.4 \mathrm{ml} / \mathrm{min}$ and the colour profile was photometrically determined. In all cases sy mmetrical profiles were obtained. These profiles were transposed to Gaussian sum frequency paper and the full width $(2 P<0.1)$ regarded as an indirect measure for the gradient disturbance. Theoretically the thickness of the band in the chamber should be $1.8 \mathrm{~mm}$. Experimentally, however, a 2.5 -fold increase of the band width was observed. In both chambers this value was similar and constant up to a flow rate of $60 \mathrm{ml} / \mathrm{min}$ (Fig. 3). Larger filling rates were not tested. When the filling rate $(25 \mathrm{ml} / \mathrm{min})$ was kept constant and the draining

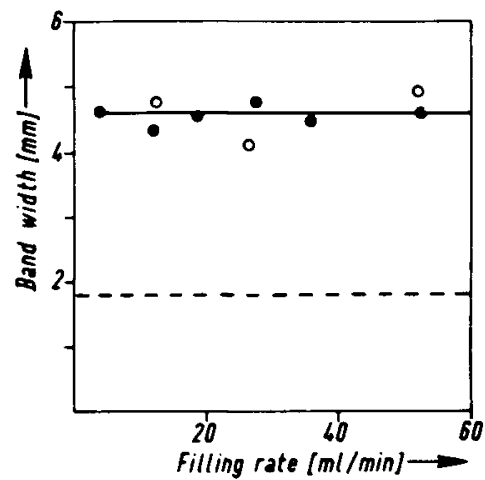

Fig. 3. Gradient disturbance through filling and draining. A $50 \mathrm{ml}$ portion of the inflowing gradient was stained with Trypan blue $(0.02 \% \mathrm{w} / \mathrm{v})$ and the full width of the colour band determined at various filling rates (draining rate $11.4 \mathrm{ml} / \mathrm{min}$ ). $\bullet$ band width in the multiple inlet chamber; $O$ band width in the single inlet chamber; - - theoretical band thickness. rate varied up to $100 \mathrm{ml} / \mathrm{min}$ the band width remained unaltered.

The following conclusions may be drawn.

1. With the presently used chamber size no difference in the gradient disturbance during filling and draining was observed in chambers with single or multiple inlets.

2. The disturbance seems to show a constant value over a broad range of gradient flow rates.

This observation is of some interest with respect to the separation power, which is limited by the "streaming" effect ${ }^{[4-6,9]}$, and the thickness of the starting band. Thus the sample processing rate can be only increased by enlarging the chamber diameter. If only one inlet and outlet is available the draining rates limit the chamber size via the tolerable fractionation time ${ }^{\mid 1]}$. If, however, multiple inlets and outlets are available the chamber size will be only limited by the number of inlets available.

\section{Disturbance of the starting band}

The geometry of the starting band is an important factor in the separation resolution. If a chamber with a conically shaped base is used the simplest technique is to lift the sample with the incoming gradient to its starting position. This may have the disadvantages that

1. the starting band is disturbed by the inflowing gradient and each disturbance gives rise to a streaming effect ${ }^{|9|}$.

2. the spheres which sediment during the loading process may pass gradient layers which are not yet stabilized.

3. large and dense spheres may sediment faster then they can be lifted to the starting position ${ }^{[10]}$.

An altemative technique is to apply the cells directly to the surface of the gradient. Technically this is more difficult to perform since the cell sample must be evenly distributed over the gradient surface. This is achieved by an applicator consisting of 25 bent needles with their outlets pointing vertically upward (Fig. 1). The outlets were regularly distributed over the level of the gradient surface. The dispersion of the starting band was tested by applying $50 \mathrm{ml}$ Trypan blue stained TC solution Puck G to the gradient surface in both chambers and determining the band width photometrically after fractionation. Up to a load- 
ing rate of $5 \mathrm{ml} / \mathrm{min}$ the band width in both chambers was constantly 1.6 times higher than theoretically expected. This value contains the fractionation error too (draining rate $25 \mathrm{ml} / \mathrm{min}$ ). Even at higher sample loading rates the width of the starting band did not increase. Only at very high rates $(>20 \mathrm{ml} / \mathrm{min})$ it appeared that the sample was loaded faster than it could spread over the surface, which slightly impaired an ideal surface layer formation. This, however, can be disregarded in most cases since its contribution to dispersion is still negligibly low in comparison to the other dispersion factors.

When the sample was lifted to its starting position in the chamber with the conically shaped base the same degree of broadening was observed even at filling rates of $50 \mathrm{ml} / \mathrm{min}$.

These results show that using small chambers with one inlet and outlet the technique of sample application is of negligible influence on the disturbance of the starting band. Nevertheless the application of the sample to the top of the gradient is of advantage if

1. a chamber is used having multiple inlets and outlets

2. particles are to be separated with high sedimentation velocity

3. if chambers are to be filled at high flow rates

4. if it is of experimental convenience to fill the chambers prior to the loading of the separation sample.

\subsection{Band width and resolution}

The width of sedimenting bands depends

1. on apparative and method parameters namely

a) gradient establishment (disturbance by flow irregularities),

b) retardation because of decreasing gravitational force in increasing medium density and viscosity,

c) sample application and starting band width,

2. on radius and density variations of the particles and

3. on diffusion based instabilities as described by Mason [9] and Sartory[11].

The latter effect may be disregarded as it is hardly observable below critical threshold concentrations of particles ${ }^{|9|}$. In the following some band broadening effects were analysed.

\subsection{Apparative resolution}

The measured difference $d_{m}$ in the paths of two separated particles is the result of their differing sedimentation paths $\Delta s_{p} \times t$ and a systematic apparative error. Experience shows that this error comprises a constant value $d_{0}$ (e.g. starting band thickness) and a time dependent variable $s_{v} \times t$ where $s_{v}$ represents the result of some undefined intrinsic properties of apparatus and technique. It follows in mathematical terms

$d_{m}=\Delta s_{p} t+d_{0}+s_{v} t$;

If this equation is written in terms of relative band width $B$ we obtain

$B=\frac{d_{m}}{s_{a} t}=\frac{\Delta s_{p}}{s_{a}}+\frac{d_{0}}{s_{a} t}+\frac{s_{v}}{s_{a}} ;$

where $s_{a}$ is the average sedimentation velocity. This expression reveals that only the constant part of the error can be decreased by prolonging the separation time. The last term however is the absolute limit for improvement of band width and resolution and may partially be caused by diffusion based instabilities ${ }^{[9]}$.

A more detailed description of the first term $\frac{\Delta s_{p}}{s_{a}}$

can be derived from the sedimentation velocity $s_{p}$, which is connected to particle volume and density $\rho_{p}$ as well as the medium viscosity $\eta_{m}$ and density $\rho_{m}$ by comparing the gravitational and frictional forces acting on the particle according to Stoke's law. Assuming the particles to be spheres $s_{p}$ is explicitly given as

$s_{p}=\frac{2}{9} g \frac{r^{2}\left(\rho_{p}-\rho_{m}\right)}{\eta_{m}} ;$

where $g$ stands for gravity. From this equation we get the term $\frac{\Delta s_{p}}{s_{a}}$ as the
total relative differential.

Further, assuming viscosity and gravity to be constant, this differential may be written as

$\frac{\Delta s_{p}}{s_{a}}=2 \frac{\Delta_{r}}{r_{a}}+\frac{\Delta \rho_{p}}{\rho_{p a}-\rho_{m a}} ;$

where index $a$ indicates values averaged for two particles differing by $\Delta r$ and $\Delta \rho_{p}$. This implies that relative band width depends on both particle properties: radius and density. 


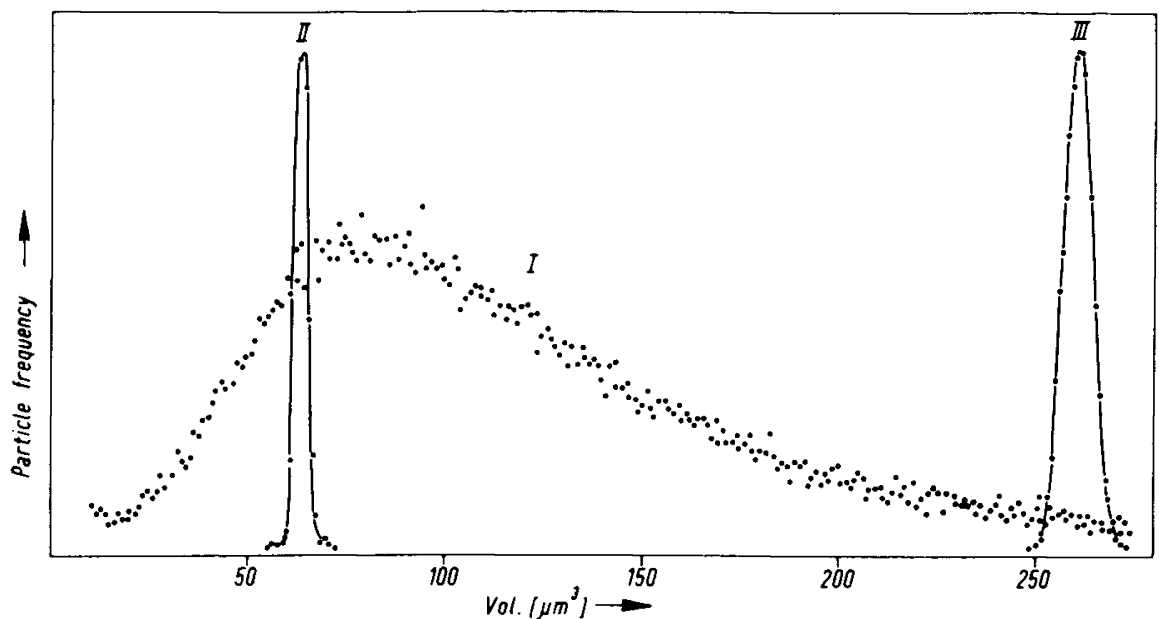

Fig. 4. Volume histogram of polystyrene spheres.

I, Dow Latex 41961 (Serva Heidelberg), diameter $5.7 \mu \mathrm{m}$; II, microspheres (Particle Technology Inc. Los Alamos), diameter $5.0 \mu \mathrm{m}$; III, microspheres (Particle Technology Inc. Los Alamos), diameter $7.9 \mu \mathrm{m}$.

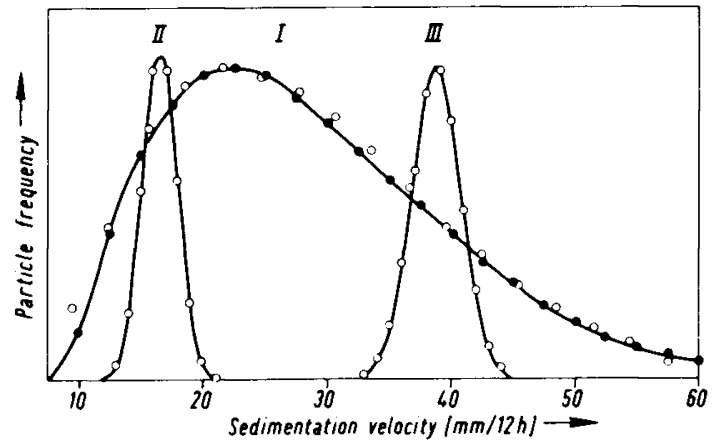

Fig. 5. Sedimentation histograms of Dow Latex particles (Fig. 4 ; I - III) obtained with a single inlet $(\bullet)$ and a multiple inlet $(O)$ chamber.

Sample volume applied: $50 \mathrm{ml}$; sample concentration of the starting band; $5 \times 10^{6}$ particles $/ \mathrm{ml} ;$ Fraction volume: $14 \mathrm{ml}$; Sedimentation time: $12 \mathrm{~h}$.

In order to estimate the apparative error the variations of both particle properties must be kept negligibly small.

In this case with increasing sedimentation time (or sedimentation path) the relative band width will asymptotically approach a constant value $\left(\frac{s_{v}}{s_{a}}\right)$. This value, being defined as the smallest distinguishable difference in sedimentation velocity $\Delta s_{p}$ related to the average sedimertation velocity $s_{a}$, is called the resolution $R$ and describes an apparative parameter.

$R=\frac{\Delta s_{\min }}{s_{a}} ;$

This parameter was determined in the following manner.

Polystyrene particles, being heterogeneous in size (Fig. 4) but homogeneous in density, were loaded at various particle concentrations $\left(2.5 \times 10^{6}\right.$ particles $\left./ \mathrm{ml}\right)$ and allowed to sediment for $12 \mathrm{~h}$. Thereafter the gradient was fractionated into $13 \mathrm{ml}$ portions (Fig. 5), the volume histograms of the spheres in the single fractions electrically determined (Fig. 6), and transferred into radius square $\left(r^{2}\right)$ histograms by means of a calculator. The modes and the $90 \%$ ranges of the $\left(r^{2}\right)$ histograms were plotted versus the sedimentation velocity (Fig. 7). In a homogeneous medium a straight line is to be expected. However, in a serum gradient the retardation effect causes some deviation (Fig. 7). This is not due to differences in the particle density since for the particles in all fractions a value of $1.059 \mathrm{~g} / \mathrm{cm}^{3}$ (error $1.6 \%$ ) was calculated from the sedimentation data. For any given particle radius the $90 \%$ range of the 


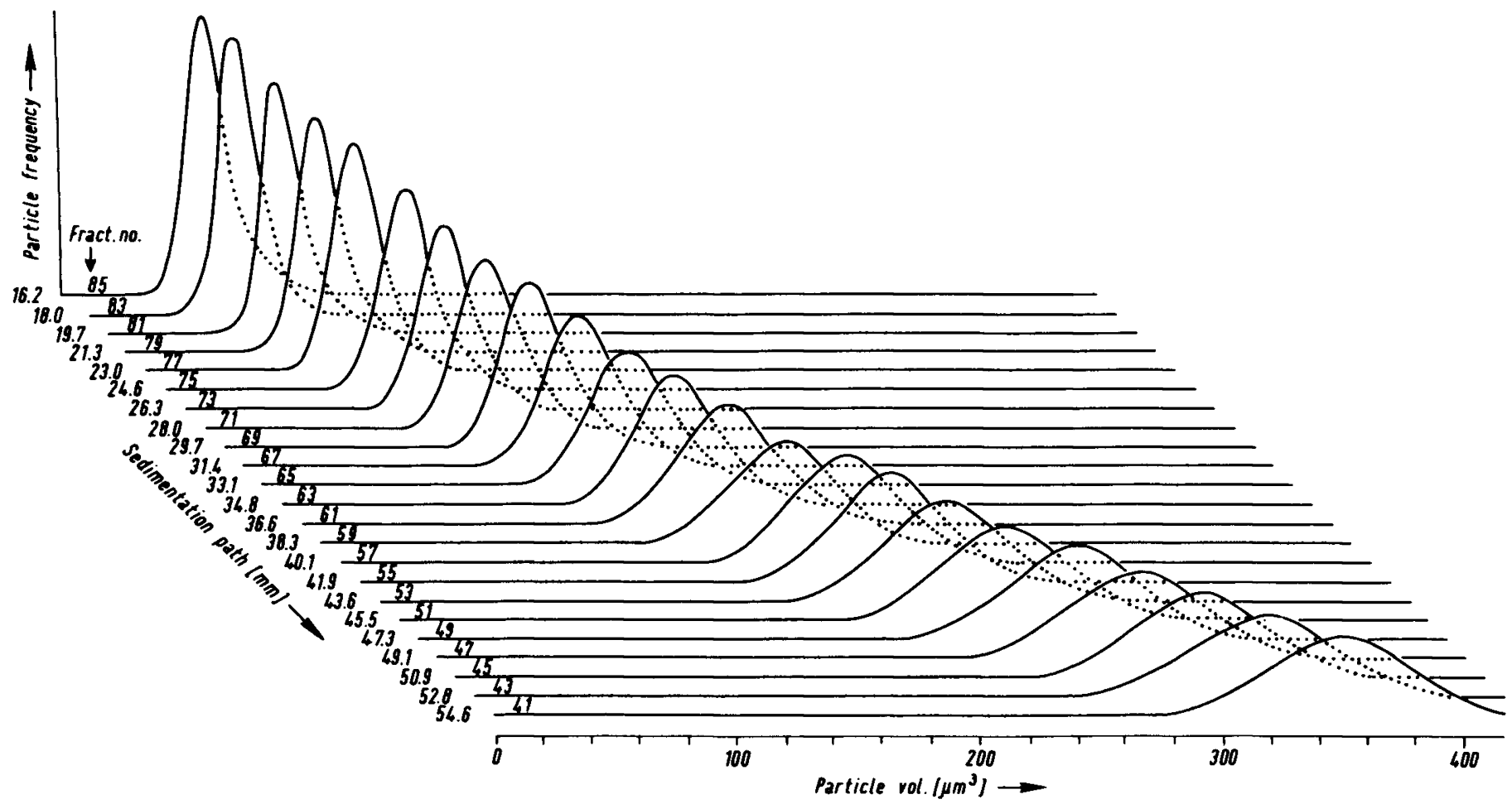

Fig. 6. Volume histograms of Dow Latex polystyrene spheres from different fractions of the sedimentation histogram shown in Fig. 5. 


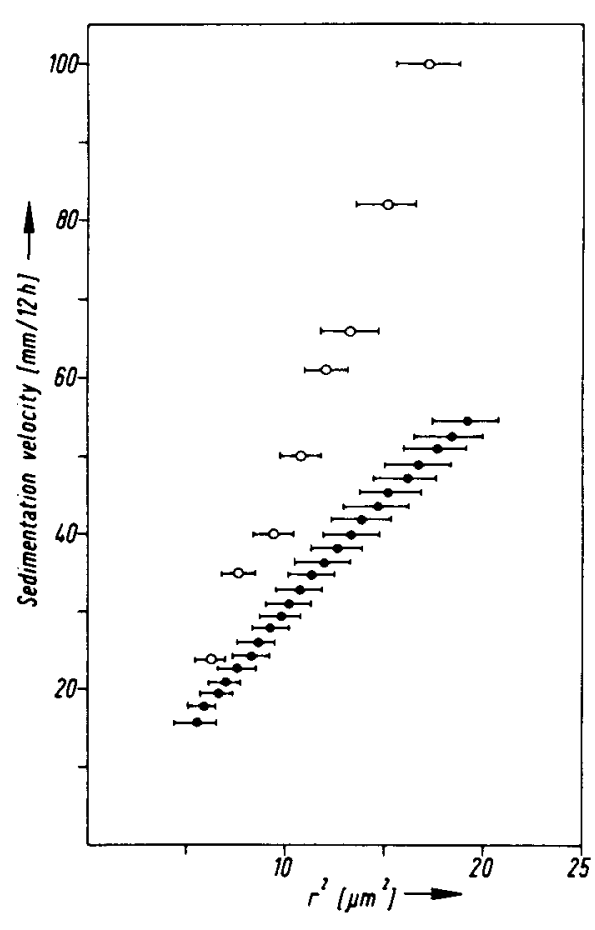

Fig. 7. Sedimentation velocity of polystyrene particles $(\bullet)$ and bone marrow cells $(0)$ as a function of the squares of their radii.

The data were obtained from Figs. 5 and 6 (further explanations see text).

sedimentation velocity distribution was determined. Since $\Delta s_{p}$ is negligibly small and $t$ is identical for all particles the ratio of these values to the average migration path can be regarded as the relative band width $B$. As predicted by equation 2 , the relative band width decreases with increasing sedimentation path and asymptotically approaches a value of 0.15 .

The validity of this approach was directly proven by use of homogeneous polystyrene microspheres with a volume of $257 \pm 7 \mu^{3}(2 P<0.1)$ and $63 \pm 3.3 \mu \mathrm{m}^{3}$ ( $\left.2 P<0.1\right)$. (Fig. 4) The particles were allowed to sediment for 6 and $12 \mathrm{~h}$, respectively, and the band width ( $90 \%$ range) directly determined from the sedimentation histogram. The resulting values for the relative band width exactly fitted the results indirectly obtained. (Fig. 8) The measurements performed in both different chambers provided the same results.
The following conclusions may be drawn.

1. The dispersion which is due to apparative errors is surprisingly small being 0.15 .

2. The resolution seems to be independent of the apparative modifications presently tested.

3. The smallest difference in the particle diameter at which complete separation is attained is $0.68 \pm 0.01 \mu \mathrm{m}$. This requires a minimum sedimentation path of $30 \mathrm{~mm}$ irrespective of the particle size.

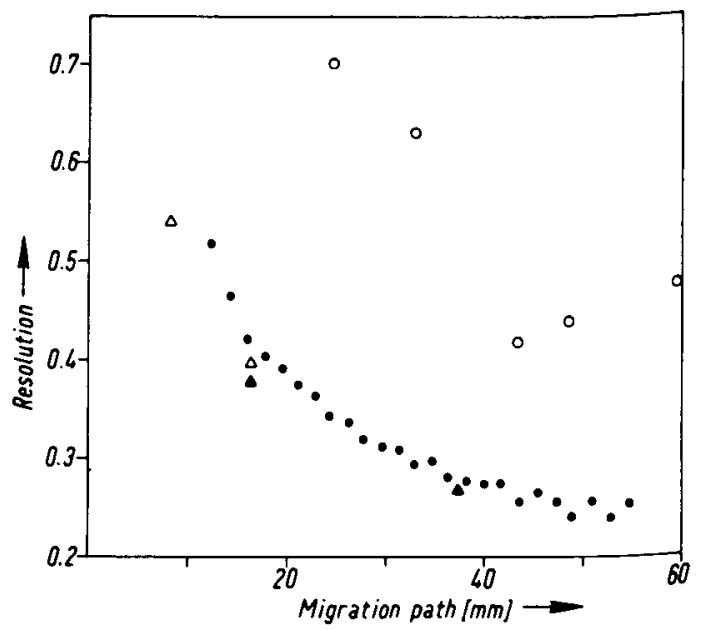

Fig. 8. Resolution of the velocity separation technique.

- Dow Latex 41961 (Serva Heidelberg), diameter $5.7 \mu \mathrm{m}$; $\triangle$ microspheres (Particle Technology Inc. Los Alamos), average diameter $5.0 \mu \mathrm{m} ; \Delta$ microspheres (Particle Technology Inc. Los Alamos), average diameter $7.9 \mu \mathrm{m}$; o Bone marrow cells of distinct volumes found in the modes of the profiles in Fig. 9.

\subsection{Separation sensitivity}

If spheres are separated showing density differences within a given size the relative band width $B$ will be also dependent on this particle property as shown by equations 2 , and 3 . Thus the particle properties will contribute to the dispersion. In order to discriminate the total dispersion from the apparative dispersion we will use the term separation sensitivity. This sensitivity $\sigma$ will be defined as the ratio of the real difference in the particle sedimentation velocity $\Delta s_{p}$ to the smal- 
lest distinguishable difference in the sedimentation velocity $\Delta s_{\min }$.

$\sigma=\frac{\Delta s_{p}}{\Delta s_{\min }}$

Thus separation sensitivity improves with increasing $\Delta s_{p}$ and decreasing $\Delta s_{\min }$. If we substitute equation 5 , by 3 , and 4 , we obtain

$\sigma=\frac{1}{R}\left(2 \frac{\Delta r}{r_{a}}+\frac{\Delta \rho_{p}}{\rho_{p a}-\rho_{m a}}\right) ;$

where $\Delta \rho_{p}$ is the difference in particle density, $\rho_{p a}$ and $\rho_{m a}$ are average densities of particle and medium respectively and $r_{a}$ is the particle radius.

In the following the particle dependent dispersion was tested with various mamalian cells. We used bone marrow cells since they comprise 1. morphologically discriminable cells, 2 . cells of distinct sizes, and 3. cells of differing densities (Table). Bone marrow cells were separated for $12 \mathrm{~h}$ in the serum gradient shown in Fig. 2 and subsequently fractionated into $10 \mathrm{~m} l$ portions. A bimodal sedimentation histogram was obtained (Fig. 9a - b) with a broad shoulder in the fast fractions, a broad peak with a mode at $60 \mathrm{~mm}$, a narrow peak with a mode at $32 \mathrm{~mm}$ and a small shoulder with a mode at $23 \mathrm{~mm}$ migration path. The volume histograms of the cells in every tenth fraction were electrically determined (Fig. 10). In contrast to the volume histograms of the polystyrene particles the volumes of the cells did not grow continuously but in discrete steps (Fig. 10). Based on this discrete pattern it was possible to fit normal distributions to the experimental histo-

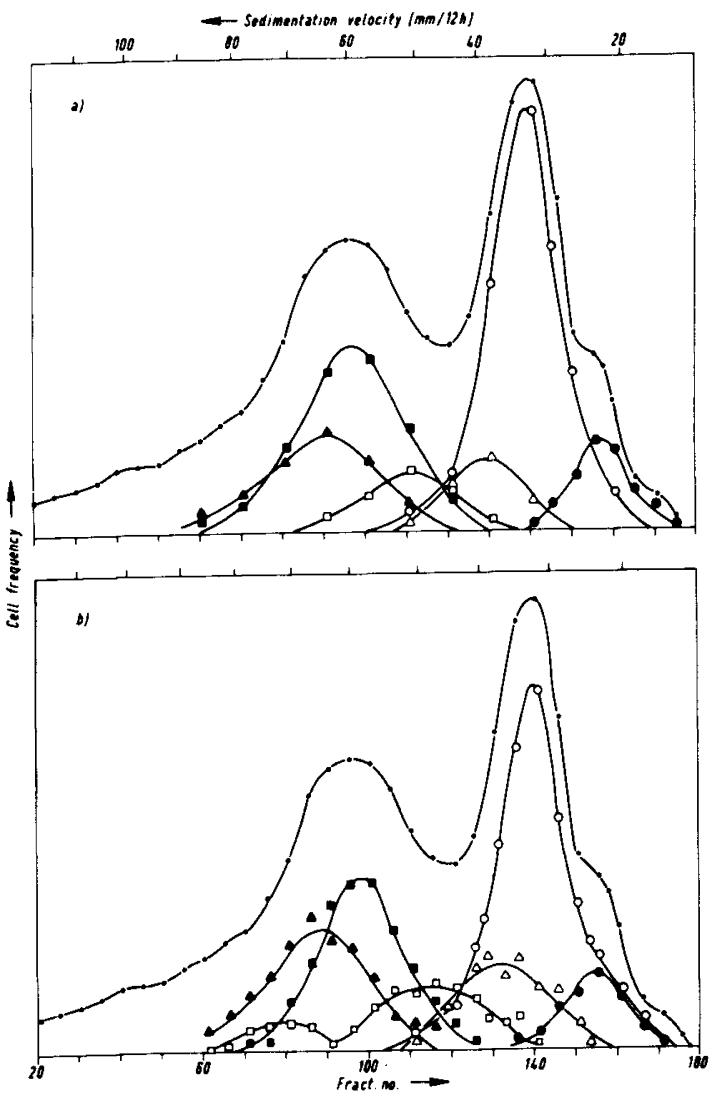

Fig. 9. Sedimentation profiles of rat bone marrow cells. a) Profiles of volume defined populations. b) Profiles of morphologically defined populations. Sedimentation time: $12 \mathrm{~h}$; sample volume applied: $50 \mathrm{ml}$; sample concentration: $5 \times 10^{6}$ cells $/ \mathrm{ml}$; fraction volume: $10 \mathrm{ml}$. For symbols see Table.

Table. Properties of bone marrow cells separated by velocity sedimentation

\begin{tabular}{|c|c|c|c|c|c|c|c|}
\hline \multirow[t]{2}{*}{ Symbol ${ }^{a}$} & \multirow{2}{*}{$\begin{array}{l}\text { Cell volume } \\
\text { (mean; } \\
2 P=0.1) \\
{\left[\mu \mathrm{m}^{3}\right]}\end{array}$} & \multirow{2}{*}{$\begin{array}{l}\text { Average cell } \\
\text { density } b \\
\qquad\left[\mathrm{~g} / \mathrm{cm}^{3}\right]\end{array}$} & \multicolumn{4}{|c|}{$\begin{array}{l}\text { Sedimentation velocity } \\
\qquad[\mathrm{mm} / \mathrm{h}]\end{array}$} & \multirow[t]{2}{*}{ Morphology $c$} \\
\hline & & & mean & s.d. & skewness & curtosis & \\
\hline $\begin{array}{l}\bullet \\
\circ \\
\Delta \\
0 \\
\bullet \\
\triangle\end{array}$ & $\begin{array}{r}66 \pm 14 \\
89 \pm 18 \\
122 \pm 22 \\
153 \pm 27 \\
184 \pm 31 \\
200 \pm 34\end{array}$ & $\begin{array}{l}1.075 \\
1.081 \\
1.082 \\
1.094 \\
1.095 \\
1.092\end{array}$ & $\begin{array}{c}2.02 \\
2.75 \\
3.65 \\
3.99 \\
4.98 \\
-\end{array}$ & $\begin{array}{l}0.37 \\
0.44 \\
0.34 \\
0.41 \\
0.58 \\
-\end{array}$ & $\begin{array}{r}0.14 \\
0.01 \\
-0.04 \\
0.00 \\
0.17 \\
-\end{array}$ & $\begin{array}{r}-0.55 \\
0.00 \\
-0.50 \\
-0.31 \\
-0.32 \\
-\end{array}$ & $\begin{array}{l}\text { lymphocytes } \\
\text { lymphocytes } \\
\text { lymphocytes } \\
\text { erythroblasts } \\
\text { granulocytes } \\
\text { immature granulocytes }\end{array}$ \\
\hline
\end{tabular}

a Symbols shown in Fig. 9. b Calculated from the sedimentation data. c Differentiated in Giemsa stained smears. 


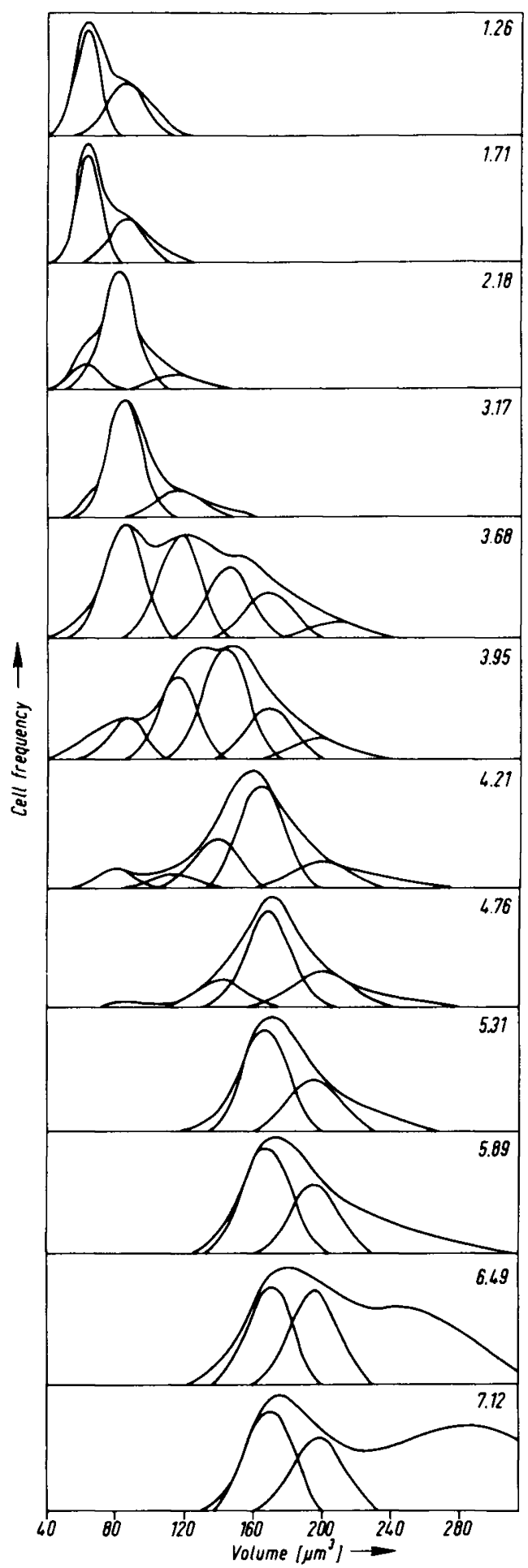

grams. (The analysis will be published in detail elsewhere.) A comparison of these fits in consecutive fractions of the sedimentation histograms revealed that the parameters of single distributions did not change over a relatively wide range of sedimentation velocity. On this basis it seemed useful to calculate the distribution of these size-defined populations in the velocity sedimentation profile. It turned out that various different, rather symmetrical profiles were obtained. (Fig. 9b, table). However these profiles were different from normal distributions by slight positive or negative curtosis. This is in some contrast to the Latex particles which, if they show normal distributions in size, also show normal distributions in sedimentation.

The most rational explanation is that density variation contributes to the sedimentation variation, and that density and size variation are not closely correlated. The fact that each size-defined sedimentation profile can be correlated to a certain cell type as suggested by a comparison of Figs. $9 \mathrm{a}$ und $\mathrm{b}$ supports the validity of the analysis.

The contribution of density to the band dispersion was roughly estimated by the ratio of the $90 \%$ range of the sedimentation profile of a sizedefined cell population to the average migration path. It turned out that

1. optimal separation is attained after a migration path of approximately $30 \mathrm{~mm}$,

2. the dispersion factor is 2 to 2.5 -fold larger than for Latex particles.

This implies that the density considerably contributes to the resolution of the system. Since a modification of the term $\frac{\Delta \rho_{p}}{\rho_{p a}-\rho_{m a}}$ is hardly possible without negatively influencing the cell viability, the separation sensitivity for cells can hardly be improved.

\section{Discussion}

In the present work the velocity sedimentation technique for cell separation was analysed with

Fig. 10. Volume histograms of bone marrow cells found in different fractions of the sedimentation profile.

The inner curves are Gaussian fits to the total profile (solid line). Values are sedimentation velocities in $\mathrm{mm} / \mathrm{h}$. 
respect to separation resolution, sensitivity and power. It turned out that (if the contribution of starting band thickness, fraction volume and streaming effect is minimized) the best resolution presently obtained was surprisingly small being 0.15 . This value could not be lowered by apparative modifications which influence the chamber filling and draining or the application of the starting band. The factors contributing to this value could not be clarified. This implies that technical modifications are of no use if better resolutions are to be achieved. Such modifications are only justified if the separative power or the operational convenience are to be improved. However, none of the hitherto developed modifications $[8,10,12]$ are real improvements in comparison to the simple technique described by Peterson and Evans ${ }^{[4]}$ and Miller and Phillips ${ }^{[5]}$. This also holds good for the multiple inlet chamber. The only advantage is that the separation power can be considerably increased since the chamber size is not limited by the flow rates and thus the fractionation time. In laboratory practice, however, a combination of chambers according to Miller and Phillips ${ }^{[5]}$ will be more convenient due to its technical simplicity. Of some advantage is the sample application technique presently developed. It allows the cell sample to be loaded on top of the gradient within a very short time independent of the chamber size or gradient filling.

When separating mammalian cells the particle density considerably contributes to the dispersion of the sedimenting bands. When bone marrow cells were separated, five populations could be identified by morphology and size in the sedimen. tation histograms. A comparison of the size histograms in consecutive fractions of the sedimentation profile revealed that the distribution parameters do not change over a wide range of sedimentation velocity. The cells within these distributions showed symmetrical sedimentation profiles. Based on these data, a calculation of the dispersion factor resulted in a value twice that observed for the Latex particles of uniform density. In agreement with the theory the density contributes to the cell dispersion. A further observation was that density and volume variation are not closely correlated, though some correlation exists between the modal values. This was suggested by the observation that Latex particles which show linear normal distributions in their size histograms also show linear normal distributions in the sedimentation histograms. In contrast, cells which show normal distributions in their size histograms show positive or negative curtosis in the sedimentation histograms, though banding rather symmetrically. The practical implication of the present results is that

1) apparative and methodical modifications cannot really improve the separation sensitivity for cells, and

2) definition of biological populations based on sedimentation data must be considered carefully.

Altogether, it seems that the cell separation technique of velocity sedimentation has attained a level which can hardly be improved with respect to separation resolution.

The authors thank Prof. K. Hannig for his generous support of the work and Dr. R.G. Miller for valuable discussions. The help of Mr. W. Dersch, Mr. B. Gerschütz, Mr. K. Goetz and Mr. H. Berger in the construction of the apparatus and the technical assistance of Miss $R$. Wiemeyer and Mrs. $C$. Eckelt are gratefully acknowledged.

\section{Literature}

1 Miller, R.G. (1973) in New Techniques in Biophysics and Cell Biology (Pain, R.H. \& Smith, B. J., eds.) Vol. 1, pp. 87-112, John Wiley \& Sons, Inc., New York, London, Sydney, Toronto.

2 Fulwyler, M. J. (1965) Science 150, 910 - 911.

3 Mel, H.C. (1963) Nature (London) 200, 423 - 425.

4 Peterson, E. A. \& Evans, W.H. (1967) Nature (London) $214,824-825$.

5 Miller, R.G. \& Phillips, R.A. (1969) J. Cell Physiol. 73, $191-202$.

6 Mel, H.C. (1964) J. Theor. Biol. 6, $181-200$.

7 MacDonald, H. R. \& Miller, R.G. (1970) Biophys. J. $10,834 \cdot 842$.

8 Thom, R., Hampe, A. \& Sauerbrey, G. (1969) Z. Gesamte Exp. Med. 151, 331 - 349.

9 Mason, D.W. (1976) Biophys. 16, 407 - 416.

10 Nakeff, A. \& Maat, B. (1974) Blood 43, 591 - 595.

11 Sartory, W. K. (1969) Biopolymers 7, $251-263$.

12 Mel, H.C. (1964) J. Theor. Biol. 6, $159-180$.

Priv.-Doz. Dr. K. Zeiller, Dipl.-Biol. E. Hansen, Dipl.-Biol. D. Leihener, Dipl.-Chem. G. Pascher und Dipl.-Phys.

H. Wirth, Max-Planck-Institut für Biochemie,

D.8033 Martinsried bei München. 